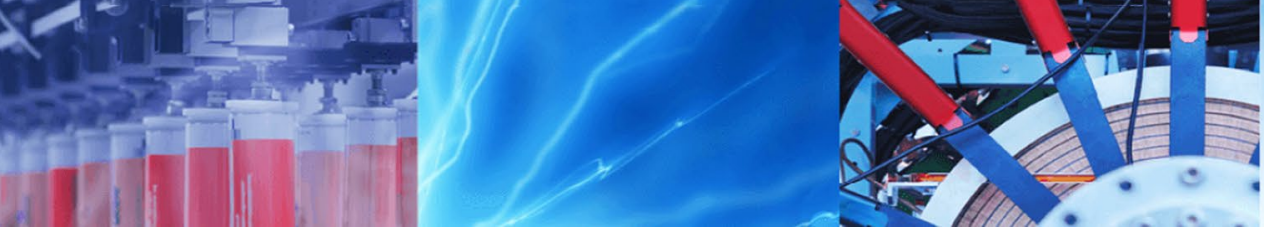

Research Article

\title{
Growth, characterisation and applications of $L$ lysine zinc sulphate crystals
}

\author{
P. Sagunthala ${ }^{1}$ (D) P. Yasotha ${ }^{1}$
}

(c) Springer Nature Switzerland AG 2019

\begin{abstract}
L lysine zinc sulphate single crystals were developed by solution growth slow evaporation method at ambient temperature using deionised water solvent. Single and powder XRD confirmed the crystalline nature and the lattice parameters identified that the grown crystal crystallised in monoclinic crystal system with the space group of $C_{2 / c}$. FTIR analysis substantiated the findings of XRD. Optical analysis proved that the grown crystal had wide transparency window (78\%) with the lower cut off value $230 \mathrm{~nm}$ and its band gap energy was $5.3 \mathrm{eV}$. High dielectric constant and high dielectric loss at low frequency and vice versa guaranteed their applications. When assayed against select bacterial strains and in vitro human cervical cancer cell line (HeLa), the grown crystal established its efficiency as potential pharmaceutical drug. It showed $100 \%$ cancer cell inhibition at very low sample concentration of $50 \mu \mathrm{g} / \mathrm{ml}$ with the $\mathrm{IC}_{50}$ value of $28.84 \mu \mathrm{g} / \mathrm{ml}$.
\end{abstract}

Keywords Single crystal $\cdot$ Optically active $\cdot$ Dielectric materials $\cdot$ Anticancer $\cdot$ Anti bacterial

\section{Introduction}

Single crystals of organic material find extensive optoelectronic applications such as optical frequency conversion, communication, data storage and switches. However, their use is constrained by their poor mechanical and thermal properties; and low laser damage threshold. The pure inorganic materials have excellent mechanical and thermal properties but possess relatively modest optical nonlinearities due to lack of extended $\pi$-electron delocalization. Owing to these problems, new types of hybrid materials have been explored from organic and inorganic complexes to combine the favourable properties of both $[1,2]$.

Organic crystals composed of amino acids are deeply probed due to its chirality. This chirality induces an asymmetric molecular structure, weak van der Waals and hydrogen bonds. Amino acids generally possess the following properties: absence of strongly conjugated bonds, wide transparency ranges in the visible and UV spectral regions and zwitterionic nature of the molecule [3]. Crystalline salts of optically active amino acids such as $L$ arginine, $L$ histidine and $L$ lysine have been intensively studied [4]. $L$ lysine-a-amino acid, contains a-amino group (in the protonated $-\mathrm{NH}_{3}{ }^{+}$form) and a-carboxylic acid group (in the deprotonated $-\mathrm{COO}^{-}$form). It possesses a side chain $\left(\left(\mathrm{CH}_{2}\right)_{4} \mathrm{NH}_{2}\right)$ with hydrogen atoms. This side chain offers a charge transfer to form metal organic crystals [5]. It is extremely unstable under normal conditions [6]. Therefore, to improve the stability the form of $L$ lysine need to be altered by adding the salts of acid and basic bases. In anticipation of combining favourable properties of inorganic salt and organic amino acid [L lysine], an attempt has been made in this study to explore the possibilities of obtaining a promising material. In this work, L lysine has been added with $\mathrm{ZnSO}_{4} \cdot \mathrm{H}_{2} \mathrm{O}$, a transition metal sulphate to grow single crystals. For the sake of simplicity and ease of use in report writing, $\mathrm{ZnSO}_{4} \cdot \mathrm{H}_{2} \mathrm{O}$ is termed as $\mathrm{ZS}$ hereafter.

P. Sagunthala, saguphy@gmail.com; P. Yasotha, yasophysics@gmail.com | Department of Physics, Sri Vasavi College, Erode, Tamil Nadu, India.

SN Applied Sciences (2019) 1:1109 | https://doi.org/10.1007/s42452-019-1119-7

Received: 26 May 2019 / Accepted: 17 August 2019 / Published online: 28 August 2019 


\section{Materials and methods}

Hydrated metal (II) sulphate of zinc $\left(\mathrm{Zn}^{2+}\right)$, and L lysine mono hydrochloride were used to grow crystals by solution growth, slow evaporation technique at room temperature. As $L$ lysine is insoluble in water at room temperature, it was taken in the form of $L$ lysine mono hydrochloride for the preparation of crystals. The chemicals used for this work were of analytical grade. Saturated solution of $L$ lysine $(65 \mathrm{~g} / 100 \mathrm{ml})$ was prepared using deionised water at room temperature using REMI $1 \mathrm{MLH}$ magnetic stirrer. Saturated solution of ZS (59.82 g/100 ml), was also prepared in the same manner. The saturated solution of $\mathrm{L}$ lysine was added with that of ZS in the ratio 1:3 and it was stirred about $5 \mathrm{~h}$ using magnetic stirrer to obtain homogeneous solution. Then this mixture was filtered twice with micro-sized pore Whatman No. 1 filter paper, covered with perforated aluminium foil and kept in a clean environment without any interruption, for slow evaporation of the water solvent under periodic observation. Nucleation followed by the growth of crystals took place and good crystals of optimum size $\left(7 \times 5 \times 8 \mathrm{~mm}^{3}\right)$ were harvested after a growth period of 82 days and it is shown in Fig. 1.

Recrystallization was carried out repeatedly to enhance the purity of the crystals. This grown crystal was named as LLZS (L lysine zinc sulphate in the ratio 1:3). The expected chemical reaction is given hereunder.

$$
\begin{gathered}
\mathrm{ZnSO}_{4} \cdot \mathrm{H}_{2} \mathrm{O}+\mathrm{HO}_{2} \cdot \mathrm{CCH}\left(\mathrm{NH}_{2}\right)\left(\mathrm{CH}_{2}\right)_{4} \mathrm{NH}_{2} \mathrm{HCl}->> \\
{\left[\mathrm{NH}_{3}^{+}-\left(\mathrm{CH}_{2}\right)_{4} \mathrm{CH}-\left(\mathrm{NH}_{2}\right)-\mathrm{COO}^{-}\right]_{2} \mathrm{ZnSO}_{4}}
\end{gathered}
$$

\section{Results and discussion}

The grown crystals were subjected to different characterization analyses in order to know their structural, functional, optical and dielectric behaviour. They were also tested for their anti bacterial and anticarcinogenic

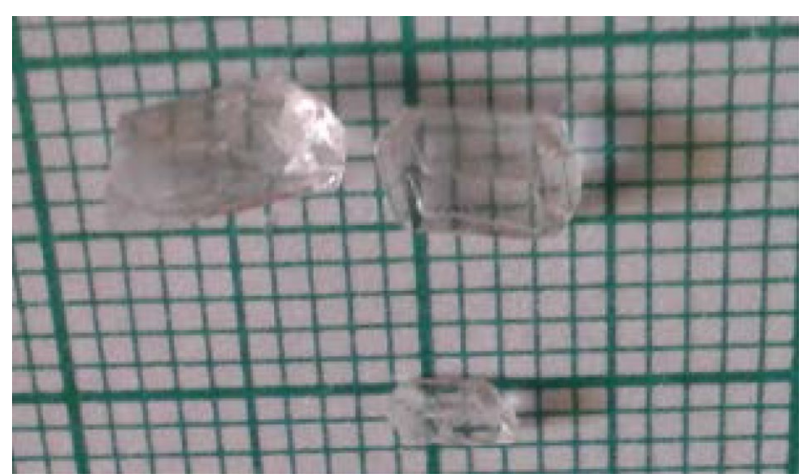

Fig. 1 Photograph of the grown LLZS crystal activities to know their potential to act as pharmaceutical drugs. The corresponding results obtained in the aforesaid analyses are discussed in detail hereunder.

\subsection{XRD analyses}

Powder X-ray diffraction (PXRD) pattern was recorded using a Rich Seifert diffractometer with Cu Ka $(\lambda=1.5418 \AA)$ radiation by crushing the grown crystals into fine powder. The samples were scanned over the range $10^{\circ}-90^{\circ}$ at the rate of $1^{\circ}$ per minute. Miller indices were estimated by $X$ powder software. The indexed PXRD patterns of the grown crystals are shown in Fig. 2. The prominent, well-resolved Bragg's peaks at specific $2 \theta$ angles reveal high degree of crystalline nature of the grown crystals. The grown crystals had also been subjected to single crystal XRD, employing a Bruker AXS diffractometer using MoKa radiation $(\lambda=0.71073 \AA)$. The results obtained are consolidated in Table 1, along with the lattice parameters of parent materials-ZS and L lysine, enabling a comparison.

PXRD pattern of the grown LLZS crystal contains peaks corresponding to $Z S$ and $L$ lysine. The results obtained from XRD analysis reveal that the grown LLZS crystals acquire the monoclinic crystal system with space group $C_{2 / c}$. Lattice parameter values prove that when $L$ lysine is added with ZS, the grown LLZS crystal crystallizes in the crystal structure of $\mathrm{ZnSO}_{4} \cdot 6 \mathrm{H}_{2} \mathrm{O}$ [7-9].

\subsection{FT-IR analysis}

The vibrational spectrum of a molecule is considered to be a unique physical property and is characteristic of the molecule. The infrared spectrum can be used as a fingerprint for the identification of functional groups by comparison with previously recorded reference spectrum [10].

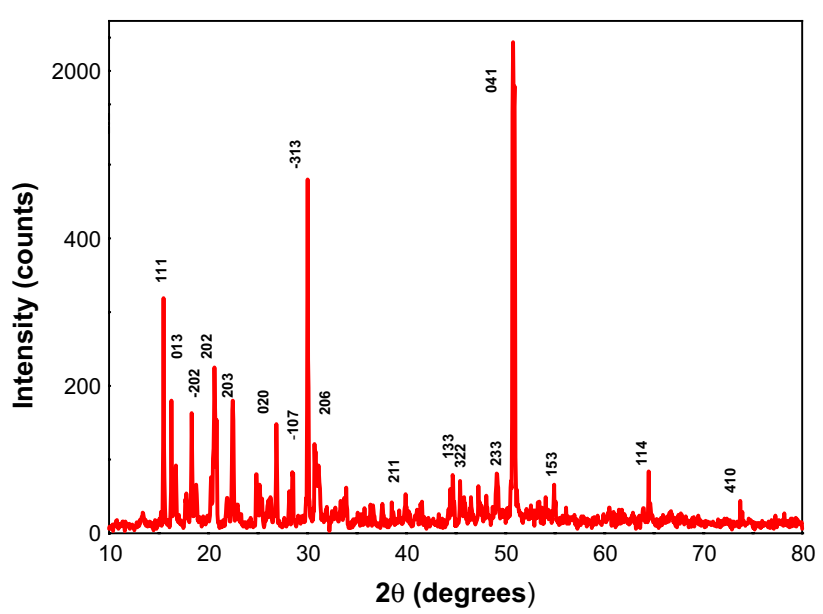

Fig. 2 Powder XRD pattern of LLZS crystal

\section{SN Applied Sciences}


Table 1 Lattice parameters of LLZS crystals

\begin{tabular}{llrrlrlll}
\hline Crystals & \multicolumn{6}{l}{ Lattice parameters } \\
\cline { 2 - 8 } & $\mathrm{a}(\AA)$ & $\mathrm{b}(\AA)$ & $\mathrm{c}(\AA)$ & $\mathrm{a}\left({ }^{\circ}\right)$ & \multicolumn{1}{c}{$\beta\left(^{\circ}\right)$} & $\gamma\left(^{\circ}\right)$ & Volume $\left(\AA^{3}\right)$ & Crystal system \\
\hline LLZS & 9.97 & 7.24 & 24.19 & 90 & 98.46 & 90 & 1726.8 & Monoclinic \\
ZS & 7.57 & 7.59 & 6.95 & 90 & 115.56 & 90 & 358.95 & Monoclinic \\
L lysine & 5.91 & 13.39 & 7.54 & 90 & 97.77 & 90 & 592.23 & Monoclinic \\
\hline
\end{tabular}

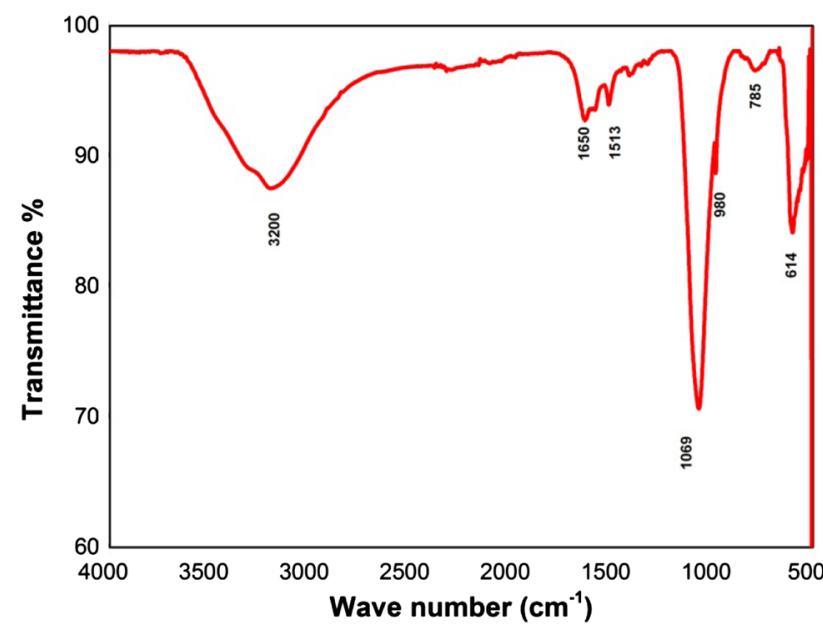

Fig. 3 FT-IR spectra of LLZS crystal

The FT-IR analysis of the grown crystals was carried out in the middle IR region between 400 and $4000 \mathrm{~cm}^{-1}$ by Perkin Elmer spectrophotometer using $\mathrm{KBr}$ pellet technique. The peak assignments for the recorded spectra are shown in Fig. 3. The broad envelope around $3200-2500 \mathrm{~cm}^{-1}$ indicates the presence of water and it belongs to free water symmetric stretching [11].

The asymmetric stretch of sulphate appears between 1200 and $950 \mathrm{~cm}^{-1}$. Usually four normal modes are present in the infrared region for the sulphate anion $\left(\mathrm{SO}_{4}{ }^{2-}\right)$ : a nondegenerate symmetric bending $\left(\approx 980 \mathrm{~cm}^{-1}\right)$, a doubly degenerate symmetric bending $\left(\approx 610 \mathrm{~cm}^{-1}\right)$, triply degenerate symmetric stretching $\left(\approx 1080 \mathrm{~cm}^{-1}\right)$ and triply degenerate symmetric bending $\left(\approx 1150 \mathrm{~cm}^{-1}\right)$. Changes in protonation, metal complexation and solvation of $\mathrm{SO}_{4}{ }^{2-} \mathrm{can}$ modify $\mathrm{S}-\mathrm{O}$ bond length and it changes the symmetry of the anion as a result. This leads to a shift in the vibrational bands to different wave numbers and causes the degenerate vibrations into non-degenerate $[7,8,12]$.

The results of FTIR analysis of the grown LLZS crystal reveal that most of the prominent peaks obtained are due to sulphate ion and water molecules. In addition, they also contain the peaks corresponding to the functional groups of $\mathrm{L}$ lysine viz., $\mathrm{NH}_{3}{ }^{+}, \mathrm{NH}_{2}, \mathrm{COO}^{-}, \mathrm{C}-\mathrm{H}$ and $\mathrm{CH}_{2}$ as listed in the Table 2. This proves the presence of $\mathrm{L}$ lysine in the grown LLZS crystal $[2,6,13]$.
Table 2 Band assignment of LLZS crystal

\begin{tabular}{ll}
\hline Band assignment & Wave number $\mathrm{cm}^{-1}$ \\
\hline $\mathrm{O}-\mathrm{H}$ & 3200 \\
$\mathrm{NH}_{3}{ }^{+}$ & 1660,1069 \\
$\mathrm{NH}$ & 3200 \\
$\mathrm{COO}^{-}$ & $1660,1069,785$ \\
$\mathrm{C}-\mathrm{H}$ & 980 \\
$\mathrm{CH}_{2}$ & $1069,855,785,614$ \\
$\mathrm{SO}_{4}{ }^{2-}$ & $1069,980,614$ \\
\hline
\end{tabular}

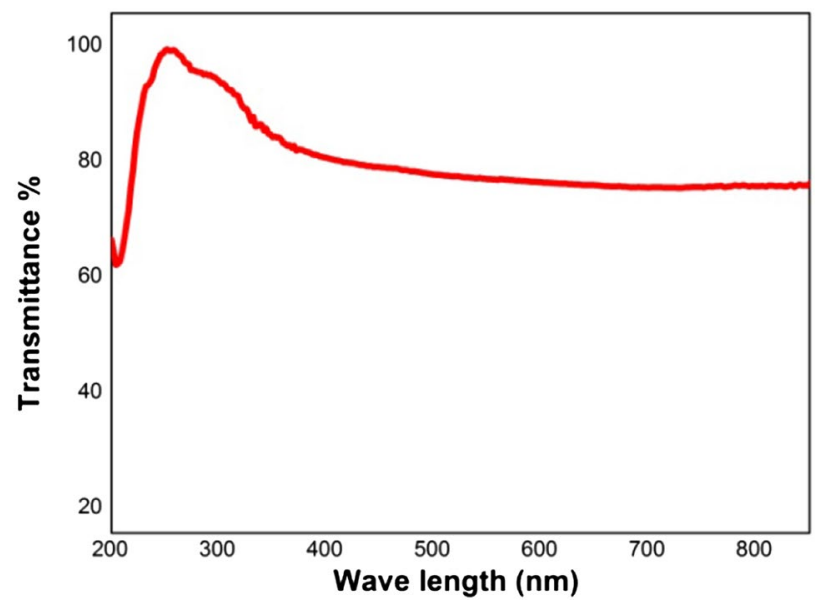

Fig. 4 UV-visible spectra of LLZS crystal

\subsection{Optical studies}

The optical transmission spectra of the grown crystals were recorded using Shimadzu UV-Vis spectrophotometer between the wavelength ranges of 200 and $1100 \mathrm{~nm}$ and is shown in Fig. 4.

From UV transmittance spectrum (Fig. 4), the grown LLZS crystal is found to be highly transparent in the wavelength range $230-800 \mathrm{~nm}$. The UV transparency lower cutoff wavelength is $230 \mathrm{~nm}$. The transmittance of the grown crystal is $78 \%$ in middle and near ultra violet and in the visible region. The band gap energy was calculated as $5.3 \mathrm{eV}$. The low cut off wavelength and the large transmittance window enable the grown crystal to be a good candidate for optical applications [14]. 


\subsection{Dielectric studies}

The dielectric analysis is an essential characteristic that can be used to get information based on the electrical properties of a material medium as a function of frequency. Based on this study, the ability of storing electric charges by the material and ability of transferring the electric charge can be evaluated. Electronic and Microelectronics industries need low dielectric constant materials as an interlayer dielectric [15]. The conventional parallel plate capacitor method was employed by coating the silver paste on the opposite faces of the crystal to get contact between crystal and electrodes using a HIOCKI 3532-50 LCR HITESTER instrument. The variation of dielectric constant $\left(\varepsilon_{\mathrm{r}}\right)$ and dielectric loss ( $\tan \delta$ ) were measured for the grown crystals at room temperature as a function of frequency ranging from $100 \mathrm{~Hz}$ to $5 \mathrm{MHz}$ (Figs. 4b, 5a).

In the present study, dielectric constant was calculated using following formula

Dielectric constant, $k=\varepsilon_{r}=\frac{C_{d}}{\varepsilon_{0} A}$

where $C$ is the capacitance, $d$ is the thickness of the pellet, $\varepsilon_{0}$ is the vacuum dielectric constant (permittivity of free space, $\varepsilon_{0}=8.854 \times 10^{-12} \mathrm{~F} / \mathrm{m}$ ) and $A$ is the area of the pellet [16].

The dielectric constant values are high at low frequencies and decreases rapidly and stabilizes. At high frequencies the electronic, ionic, dipolar and space charge polarization are predominant. Of all these polarizations only space charge is active at lower frequencies and there is loss of significance of other three polarizations which lead to low value of dielectric constant at higher frequencies [17]. The low value of dielectric constant explains the high

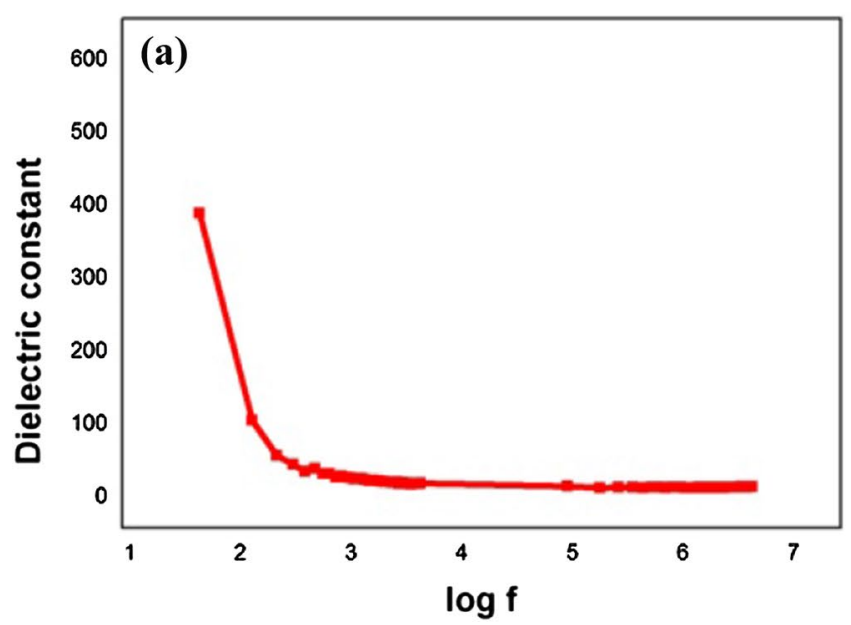

SHG conversion efficiency of the grown crystals and this is in agreement with the Miller rule. Materials with high dielectric constant at low frequency find applications in heating devices $[2,18]$.

The dielectric loss is also studied as a function of frequency at room temperature, as shown in Fig. 5b. These curves suggest that the dielectric loss strongly depends on the frequency of the applied field, similar to dielectric constant. The variation of loss tangent with frequency can be assigned to the dipole alignment when the field is applied. At low frequencies, the dipoles easily switch alignment with the changing field. The low value of dielectric loss at high frequencies suggests improvement in optical quality with lesser defects in the samples [19]. The above results are in accordance with the earlier reports [20]. Owing to lower dielectric constant and dielectric loss at high frequency, the grown crystals are suitable for use in ferroelectric, optoelectronic and photonic applications [21].

\section{Pharmacological activity}

\subsection{Introduction}

In addition to their physicochemical properties, an effort has been made in this study to investigate applicability of the grown crystals as an inhibiting agent for bacteria and cancerous cells. Bacteria are microscopic and unicellular organisms that live everywhere. Some are airborne while others live in water or soil. A bacterial infection is a proliferation of a harmful strain of bacteria inside human body. Typhoid fever, gastroenteritis and food poisoning are just a few illnesses that may be caused by harmful bacteria. Most bacterial diseases can be treated with antibiotics, although antibiotic-resistant strains have started to emerge [22, 23].

Fig. 5 Plot between a log $f$ and dielectric constant $\mathbf{b} \log f$ and dielectric loss

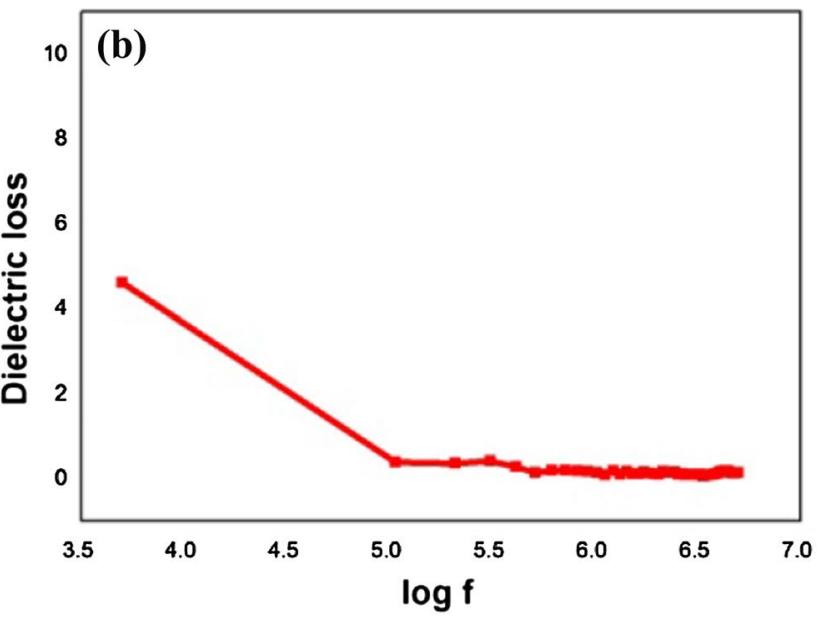


Cancer is undoubtedly one of the main health concerns facing our society and is a leading cause of death worldwide [24]. It is a disease characterised by the uncontrolled cell proliferation and the ability to invade other tissues and organs $[25,26]$. Continuous demand for new anticancer drugs has stimulated research based on the use of metals since potential drugs developed in this way may be less toxic and more prone to exhibit anti-proliferative activity against tumors [27].

\subsection{Pharmacological activities of metal complexes}

Transition metals-trace elements; constitute $0.1 \%$ of human body weight. Although these metals are present only in small quantity, they are essential for healthy functioning of human body $[6,28]$. These elements catalyze the functioning of enzymes, which are required by most biological organisms. In vivo studies have indicated that some biologically active compounds become more carcinostatic and bacteriostatic upon chelation [29]. An important property is the ability of metals to form positively charged ions in an aqueous solution that can bind to negatively charged biological molecules. The high electron affinity of metal ions can significantly polarize groups that are coordinated to them, leading to the generation of hydrolysis reactions. Recently, considerable attention has been drawn to metalorganics, and their coordinated compounds due to their biological activities as fungicides, bactericides, analgesic, anti-inflammatory, antioxidant, antitumor and insecticidal [30]. The presence of amino acids along with bio active compounds enhances their pharmacological activity [31].

Zinc is a trace mineral which is vital for the functioning of numerous cellular processes and it plays a significant role in cancer aetiology and outcome [32]. It is virtually nontoxic even at higher doses to living organisms. Coordination flexibility of zinc makes it highly adaptable to meet the needs of proteins and enzymes that carry out diverse biological functions. Zinc is required in the diet of human beings in trace quantities $(\approx 10 \mathrm{mg} /$ day) as recommended by the Food and Nutrition Board at the Institute of Medicine of the National Academies. It is the only transitional element that is neither cytotoxic nor carcinogenic. It is also non-mutagenic and non-teratogenic. Its deficiency is an important factor in the development and progression of malignancy and that it could be efficacious in the prevention and treatment of several types of cancers related to the digestive tract, brain and neck. Zinc supplementation has been shown to reduce the incidences of tumors and carcinogenic severity [33].

Keeping all these in mind, an attempt was made to investigate the biological (antibacterial and anticancer) activities of the grown crystals and the results obtained are encouraging in this direction too. Hence the grown crystals were subjected to extensive scientific and pharmacological screening to find the ability and efficacy of the grown crystals to act as sources of new drugs.

\subsection{Antibacterial activities of the grown crystals}

Antibacterial activity is the ability of a substance to inhibit bacterial infection. Different types of antibiotics are being used in the treatment of bacterial infections. Most of these antibiotics are derived from microorganisms. Development of bacterial resistance to the available antibiotics has led the researcher to investigate the antibacterial activity of the grown crystals as alternative source of drugs for the bacterial infections [34-36]. The grown crystals were analysed to find their antibacterial activity against select bacteria (both gram positive and gram negative) using well diffusion method.

Agar disc diffusion method was adopted for this in vitro investigation [37]. Antibacterial assay was used to determine the growth inhibition of bacteria. The zone of inhibition was compared with standard antibiotic disc. The antibacterial activity was recorded by measuring the width of the clear inhibition zone around each disc using zone reader $(\mathrm{mm})$ [38]. The grown crystals were screened for their antibacterial activity against select bacteria. The microorganisms used were Escherichia coli, Salmonella typhi, Staphylococcus aureus (gram positive), Bacillus subtilis and Lactobacillus (gram negative). The control value of this inhibiting zone is $7 \mathrm{~mm}$ and the inhibiting zone extends up to $25 \mathrm{~mm}$.

Effect of the grown LLZS crystal on five bacteria is given in Table 3. The photographs give clear visual images of domain up to which the inhibition took place. It is found that for the grown crystal, all the five bacteria are sensitive. The activity of LLZS is significant for the Bacillus subtilis bacterium. The sensitivity order for LLZS crystal is as follows: Staphylococcus aureus > Lactobacillus $>$ Escherichia coli $>$ Salmonella typhi $>$ Bacillus subtilis.

\subsection{Anticarcinogenic activities of the grown crystals}

Cancer is the most dreaded among the diseases and it is a major threat to human life. Cervical cancer is the leading cause of death world-wide amongst women and one-fifth of all new cases are diagnosed in India [39]. Cervical cancer commonly occurs due to chronic infection with human Papilloma virus [40]. Metal complexes have unique properties of enhancing their role as antitumor agents [30]. Hence, an effort is made to add L lysine, a biological molecule with zinc sulphate, to make it as anticarcinogenic agent against cervical cancer. The grown crystal was subjected to anticancer analysis to know their potential to act as an anticancer agent. 
Table 3 Zone of inhibition ( $\mathrm{mm}$ ) of LLZS crystal

Bacterial strains

\begin{tabular}{c|c|c|r|c}
\hline B. subtilis & E. coli & L. bacillus & S. aureus & S. typhi \\
\hline $10 \pm 0.6$ & $16 \pm 0.9$ & $17 \pm 0.7$ & $17 \pm 0.9$ & $15 \pm 0.1$ \\
\hline$B_{3}$ & $B_{4}$ & & $B_{4}$ & \\
& & & & $B_{4}$ \\
\hline
\end{tabular}

Colour highlighting indicates rate of inhibition (green indicates max and yellow indicates min)

The standard MTT assay method was utilised for this analysis. The human cervical cancer cell line (HeLa) was obtained from national centre for cell science (NCCS), Pune, India and grown in Eagles Minimum Essential Medium containing 10\% fetal bovine serum (FBS). The cells were maintained at $37{ }^{\circ} \mathrm{C}, 5 \% \mathrm{CO}_{2}, 95 \%$ air and $100 \%$ relative humidity. Maintenance cultures were passaged weekly and the culture medium was changed twice a week. The medium containing without samples were served as control and triplicate was maintained for all concentrations. The $\%$ Cell inhibition was determined using the following formula.

$\%$ Cell Inhibition $=100-$ Abs (sample) $/$ Abs (control) $\times 100$.

$I C_{50}$ was determined using GraphPad Prism software $[41,42]$.

Figure 6 shows the picture of untreated cancerous cervical cell line (HeLa). The spherical shaped images represent dead cells and the remaining images are of cervical cell line (HeLa) affected by cancer.

The grown crystal was assayed against human cervical cancer cell line and the results obtained are given in Table 4. Percentage of inhibition for different sample concentration is depicted as a bar diagram in Fig. 7 .

The LLZS crystal attains $100 \%$ cell inhibition even at a low sample concentration of $50 \mu \mathrm{g} / \mathrm{ml}$. Its $I C_{50}$ value is $28.84 \mu \mathrm{g} / \mathrm{ml}$. Hence LLZS crystal is an efficient cancer cell inhibitor.

\section{Conclusion}

Single crystals of $L$ lysine zinc sulphate-LLZS, have been grown successfully by slow-evaporation, solutiongrowth technique using aqueous medium at ambient

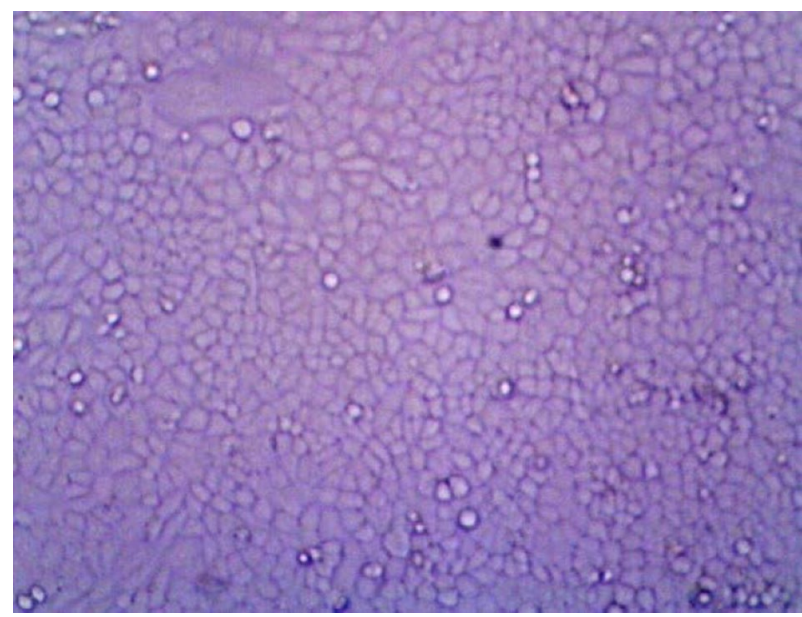

Fig. 6 Photograph of human cervical cancer cell line (HeLa)

temperature. XRD analysis confirmed the crystalline nature of the grown crystal and its structural details. The grown crystal crystallizes in monoclinic system with space group $C_{2 / c}$. Functional groups present in the grown crystals were identified through FT-IR analysis. Based on the optical analyses, the grown L lysine added zinc sulphate crystal had wide transparency window with the transmittance of $78 \%$ in the near ultra violet and entire visible region. Hence, the grown crystal is wellsuited for optical applications. Low values of dielectric constant and dielectric loss of the grown crystals at high frequency guaranteed their potential application in the fields of ferroelectrics, optoelectronics and photonics. The grown crystal showed good activity against five bacteria [Escherichia coli, Salmonella typhi, Staphylococcus aureus (gram positive), Bacillus subtilis and Lactobacillus 
Table 4 Photographs of cancerous cells treated by LLZS crystal

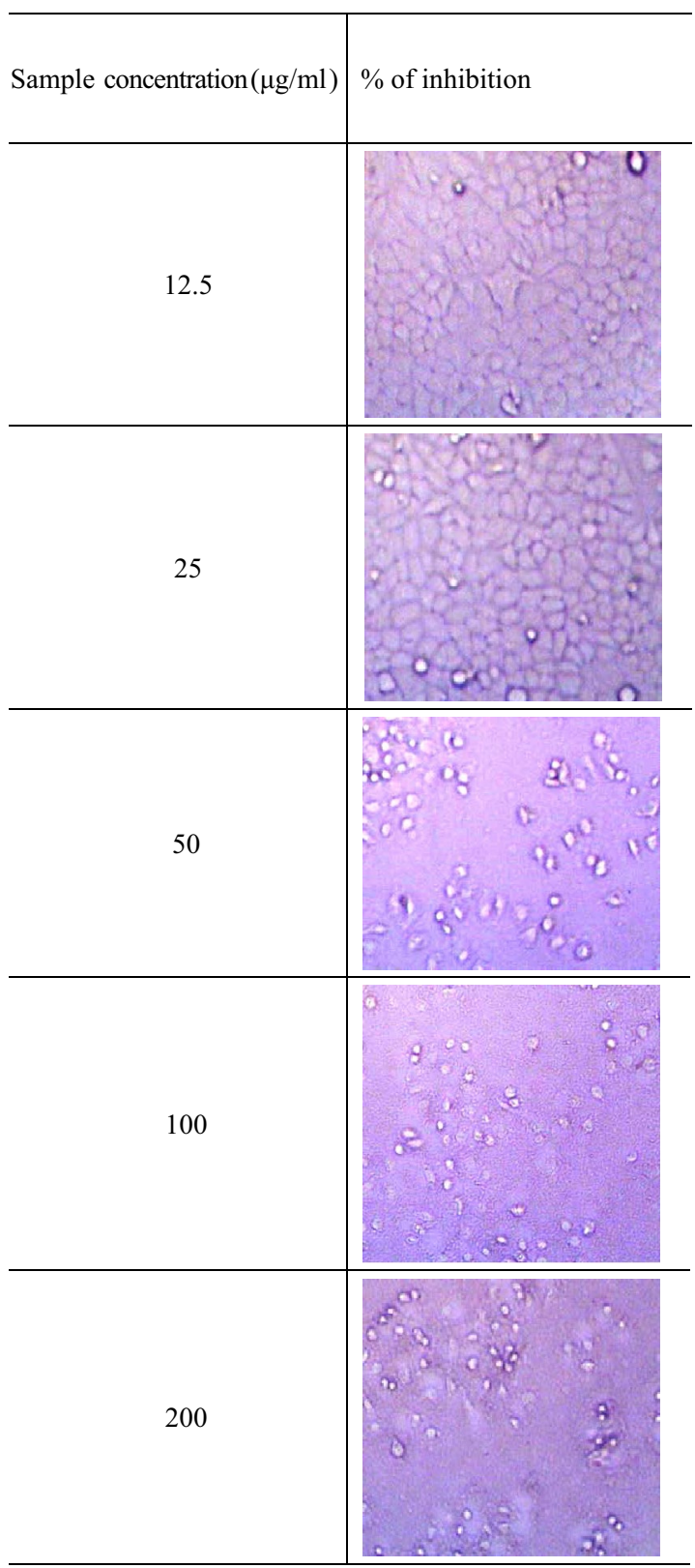

(gram negative)] which were screened. When tested against human in vitro cervical cancer cell line, the results obtained were highly favourable. It was found to possess effective anticancer activities. The LLZS crystal attains $100 \%$ cell inhibition even at a low sample concentration of $50 \mu \mathrm{g} / \mathrm{ml}$. This concentration is well within the admissible limit. Its IC $C_{50}$ value is $28.84 \mu \mathrm{g} / \mathrm{ml}$. Hence LLZS crystal is an efficient cancer cell inhibitor. Hence the grown crystals may be considered to be the main source in the formulation of antibacterial and anticancer drugs.

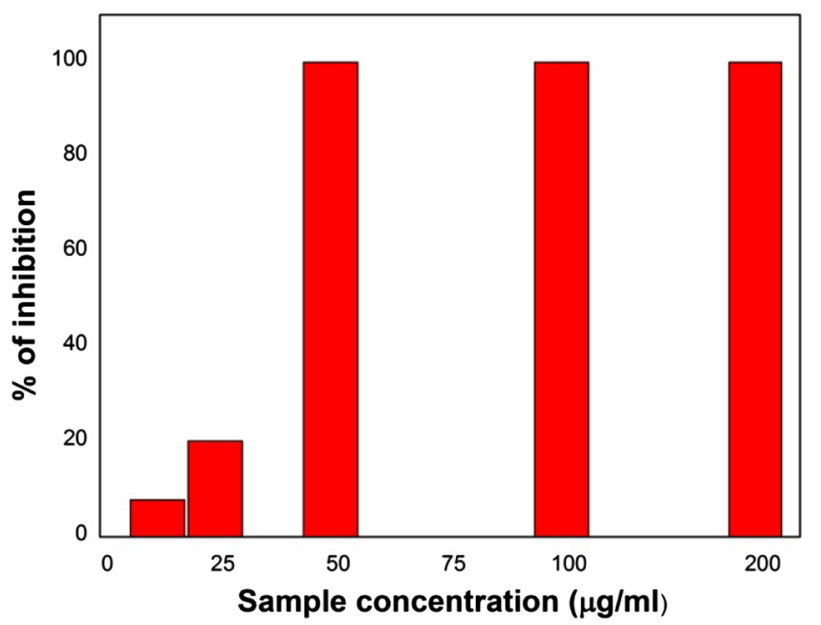

Fig. 7 Percentage of inhibition of cancer cells by LLZS crystal

Acknowledgements The authors are thankful to Indian Institute of Science, Bangalore; STIC, Cochin; PSG College of Arts and Science, $\mathrm{KMCH}$ College of Pharmacy, Coimbatore and Nandha College of Pharmacy, Erode for the facilities provided for various analysis required by this study.

\section{Compliance with ethical standards}

Conflict of interest The authors declare that they have no conflict of interest.

\section{References}

1. Rajendran V, Gnanam S (2012) Growth and characterization of co-doped L-lysine monohydrochloride dihydrate (CLMHCl) single crystals by slow evaporation method. J Chem 9(2):563

2. Lydia Caroline M, Mani G, Kumaresan S, Kumar M, Tamilselvan S, Shanmuga Sundar GJ (2015) Growth, spectral and thermal properties of sulphanilic acid single crystals in the presence of L-proline and L-lysine monohydrochloride dehydrate. Optoelectron Adv Mater 9(9-10):1239

3. Jerusha E, Shahil Kirupavathy S, Gopalakrishnan R (2016) Spectral, optical and dielectric analyses on L-lysine $\mathrm{p}$-nitrophenolate monohydrate organic crystals. Optik 127(1):420

4. Vasudevan V, Ramesh Babu R, Reicher Nelcy A, Bhagavannarayana G G, Ramamurthy K (2011) Synthesis, growth, optical, mechanical and electrical properties of L-lysine L-lysinium dichloride nitrate (L-LLDN) single crystal. Bull Mater Sci 34(3):469

5. Shaikh RN, Anis M, Shirsat MD, Hussaini SS (2014) Investigation on the linear and nonlinear optical properties of L-lysine doped ammonium dihydrogen phosphate crystal for NLO applications. IOSR-JAP 6(1(I)):42

6. Tao M, Zhu M, Chunnuan W, He Z (2015) Degradation kinetic study of lysine in lysine hydrochloride solutions for injection by determining its main degradation product. Asian J Pharmacol Sci 10(1):57

7. Puhal Raj A, Ramachandra Raja C (2012) Studies on the synthesis, spectral, optical and thermal properties of L-valine zinc 
sulphate: an organic inorganic hybrid nonlinear optical crystal. Spectrochim Acta Mol Biomol Spectrosc 97:83

8. Saha JK, Podder J (2011) Crystallization of zinc sulphate single crystals and its structural, thermal and optical characterization. J Bangladesh Acad Sci 35(2):203

9. Anderson JL, Peterson RC, Swainson I (2012) The atomic structure of deuterated boyleite $\mathrm{ZnSO}_{4} \cdot 4 \mathrm{D}_{2} \mathrm{O}$, ilesite $\mathrm{MnSO}_{4} \cdot 4 \mathrm{D}_{2} \mathrm{O}$, and bianchite $\mathrm{ZnSO}_{4} \cdot 6 \mathrm{D}_{2} \mathrm{O}$. Am Mineral 97:1905

10. Sathyalakshmi R, Bhagavannarayana G, Ramasamy P (2009) Growth and characterization of a new NLO material: L-glutamic acid hydro bromide [L-GluHBr]. Mater Res Bull 44:1097

11. Al-Salami BK, Mohammed AH, Askar KA (2014) Synthesis and characterization of new schiff bases derived from 2-hydroxybenzaldehye and amino acids and their vanadyl complexes. Res J Pharm Biol Chem Sci 5(4):1457

12. Vaitheeswari M, Mahadevan CK (2015) Growth and characterization of $\mathrm{MgSO}_{4}{ }^{*} 7 \mathrm{H}_{2} \mathrm{O}$ single crystals added with urea/thiourea. Int J Innov Res Sci Eng Technol 4(7):5951

13. Thebo KH, Shad HA, Thebod AA, Raftery J (2014) Synthesis, DNA interaction and SOD-like activities of copper (II) complexes: investigation of their DNA-interaction mechanism. Crystallogr Rep 59(7):1

14. Krishna Priya R, Mary Delphine S, Shobana S (2015) Synthesis, growth and structural characterization of semi organic nonlinear optical material: L-arginine doped zinc sulphate heptahydrate single crystal. Asian J Chem 27(2):582

15. Malliga $P$ (2014) Thermal, surface and dielectric studies of L-glycyl alanine single crystals. J Chem 6(12):359

16. Sagadevan S, Murugasen P (2015) Growth, microhardness, electrical and dielectric studies on L-alanine hydrogen chloride NLO single crystal. IJMSE 3(2):159

17. Jagadeesh MR, Suresh Kumar HM, Ananda Kumari R (2014) The molecular structure, geometry, stability, thermal and fundamental modes of vibration of glycine dimer by DFT methods. Arch Appl Sci Res 6(4):88

18. Kishore Kumar J et al (2013) Synthesis of novel thiadiazolotriazin-4-ones and study of their mosquito-larvicidal and antibacterial properties. Elixir Crystal Growth 61:17110

19. Breitbart DJ, Nawar WW (1979) Thermal decomposition of lysine. J Agric Food Chem 27(3):511

20. Hanumantharao R, Kalainathan S (2012) Growth, spectroscopic, dielectric and nonlinear optical studies of semi organic nonlinear optical crystal-L-alanine lithium chloride. Spectrochim Acta Mol Biomol Spectrosc 86:80

21. Rajasekaran R, Mohan Kumar R, Jayavel R, Ramasamy P (2003) Influence of $\mathrm{pH}$ on the growth and characteristics of nonlinear optical zinc thiourea chloride (ZTC) single crystals. J Cryst Growth 252:317

22. Workman DG, Hunter M, Dover LG, Tétard D (2016) Synthesis of novel iron (III) chelators based on triaza macrocycle backbone and L-hydroxy-2 (H)-pyridin-2-one coordinating groups and their evaluation. J Inorg Biochem 160:49

23. Theophanides T, Anastassopoulou J (2002) Copper and carcinogenesis. Crit Rev Oncol Hematol 42(1):57

24. Jevtovic V (2014) Anticancer activity of copper (II) complexes with a pyridoxal-semicarbazone ligand. Res Cancer Tumor 3(1):1
25. Fouda MFR, Abd-Elzaher MM, Abdelsamaia RA, Labib AA (2007) On the medicinal chemistry of ferrocene. Appl Organometal Chem 21:613

26. Rosenberg SA, DeVita VT Jr, Lawerence TS (2008) Cancer: principles and practice of oncology, 10th edn. Lippincott Williams \& Wilkins, Philadelphia

27. Jose GP, Santra S, Manda SK, Sengupta TK (2011) Singlet oxygen mediated DNA degradation by copper nanoparticles: potential towards cytotoxic effect on cancer cells. J Nano Biotechnol 9(9):1

28. Butler WE (2012) Ph.D thesis. Dublin City University, Ireland

29. Chohan ZH, Munawar A, Supuran CT (2001) Antibacterial role of $\mathrm{SO}_{4}{ }^{2-}, \mathrm{NO}^{3-}, \mathrm{C}_{2} \mathrm{O}_{4}{ }^{2-}$ and $\mathrm{CH}_{3} \mathrm{CO}_{2}$ anions on $\mathrm{Cu}$ (li) and $\mathrm{Zn}$ (li) complexes of a thiadiazole-derived pyrrolyl schiff base. Met Based Drugs 8(3):137

30. El-Tab AS, Mohamed Abd El-Waheed M, Wahba MA, El-Fadl AE-HA (2015) Synthesis, characterization, and anticancer activity of new metal complexes derived from 2-hydroxy3-(hydroxyimino)-4-oxopentan-2-ylidene) benzohydrazide. Bioinorg Chem Appl 2015:1

31. Shivakumar KN, Prakasha KC, Channe Gowda D (2009) Synthesis and antimicrobial activity of amino acids conjugated diphenyl methyl piperazine derivatives. J Chem 6(S1):S473

32. Grattan BJ, Freake HC (2012) Zinc and cancer: implications for LIV-1 in breast cancer. Nutrients 4(7):648

33. Dhawan DK, Chadha VD (2010) Zinc: a promising agent in dietary chemoprevention of cancer. Indian J Med Res 132(6):676

34. Subramanian V, Gowry S (2011) Antitumor activity and antioxidant role of Brassica oleracea Italica against ehrlich ascites carcinoma in Swiss albino mice. Res J Pharm Biol Chem Sci 2(3):275

35. Chatterjea MN, Shinde R (2005) Textbook of medical biochemistry, 6th edn. Aypee Publishers, New Delhi

36. Reiner R (1984) Antibiotic; an introduction. New Horn Pub. Co., Nigeria

37. Bayer AW, Kirby WMM, Sherris JC, Turck M (1966) Antibiotic susceptibility testing by a standardized single disk method. Am J Clin Pathol 45:493

38. Adegoke A, Adebayo-tayo A, Bukola C (2009) Antibacterial activity and phytochemical analysis of leaf extracts of Lasienthera africanum. Afr J Biotechnol 8(1):77

39. Surya Surendren P, Jayanthi G, Smitha KR (2012) In vitro evaluation of the anticancer effect of methanolic extract of alstonia scholaris leaves on mammary carcinoma. JAPHAC 2(5):142

40. Varshney J, Subramanian S (2014) Small is the new big-interplay of mi RNAs in cancer. Curr Sci 107(5):803

41. Mosmann T (1983) Rapid colorimetric assay for cellular growth and survival: application to proliferation and cytotoxicity assays. $\mathrm{J}$ Immunol Methods 65:55

42. Monks A et al (1991) Feasibility of high flux anticancer drug screen using a diverse panel of cultured human tumour cell lines. J Natl Cancer Inst 83:757

Publisher's Note Springer Nature remains neutral with regard to jurisdictional claims in published maps and institutional affiliations. 